УДК 821

\title{
Чжан Жуй
}

\section{ЭТИКО-ПСИХОЛОГИЧЕСКИЙ ФАКТОР В АРМЕЙСКОЙ ПРОЗЕ А. КУПРИНА И А. ГРИНА}

В статье сделан вывод о влиянии прозы Куприна на творчество Грина. Указано на биографическую основу их армейской прозы, на сходство авторских позиций в описании драматической судьбы солдата, его психологической травмы, подавления его индивидуальности армейской системой, конфликта между осознанием себя личностью и деперсонализацией, фактора страха человека, природно не способного к воинскому режиму. Отмечены следующие отличия: мотив жалости к униженному солдату Куприн усиливает за счет мотива сочувствия ему молодого офицера - протогониста и резонера, в рассказах Грина авторский двойник отсутствует; социалреволюционные взгляды Грина обусловили появление в его творчестве солдата-бунтаря, в произведениях Куприна солдат - пассивный персонаж.

Ключевые слова: А. Грин, А. Куприн, индивидуальность, образ солдата, скука, совесть, страх.

DOI: $10.35634 / 2412-9534-2021-31-5-1099-1104$

В творчестве Грина отведено не очень значительное место рассказам о солдатчине, таким как «Заслуга рядового Пантелеева» (1906), «Слон и Моська» (1906), «История одного убийства» (1910). Однако в становлении реалистической манеры повествования их роль существенна, как и в творческом наследии А. Куприна - автора рассказов «Дознание» (1894), «Ночная смена» (1899), повести «Поединок» (1905) и др. Мы допускаем, что Грин обратился к теме армии не без влияния прозы Куприна.

Хотя Грин не принадлежал к литературному окружению Куприна, но в воспоминаниях современников сохранились сведения об их знакомстве и интересе друг к друга, особенно к изображению чрезвычайных ситуаций и исключительных характеров. Оба прозаика сближались со средой, как правило, чужой для писателей того времени. По свидетельству Н. Вержбицкого, накануне их первой встречи Куприну было сообщено о том, что Грин «водил знакомство со всякого рода “бывалыми людьми" - охотниками и путешественниками, даже, кажется, собирался отправиться на Северный полюс с экспедицией лейтенанта Седова» [3, с. 230], а рассказ Грина о том, как он проник в лепрозорий, вызвал у Куприна «некоторую неприязнь» к сопернику [3, с. 231-232]. В характерах героев Грина и Куприна запечатлены яркие индивидуальности, прежде всего следует отметить их природность и созвучие свободному от обывательских условностей миру.

Общей в их творчестве была и тема армейских будней, этически и психологически ими осмысленных. В картинах военной прозы Куприна и Грина выражены их демократические настроения, звучит гуманистическая мысль о равенстве людей, раскрываются психологические глубины мирочувствования солдата и сложившиеся в армии социально-этические отношения. Оба писателя критически изобразили армейскую жизнь и выказали сочувствие бесправному солдату.

Можно предположить, что в сходстве их армейской прозы определяющее значение имело сходство биографий. Грин начал службу в армии в 1902 г. солдатом 213-го Оровайского резервного пехотного батальона, дислоцированного в Пензе; через шесть месяцев он дезертировал, был пойман и вновь дезертировал. В результате короткой солдатской службы он пришел к выводу о несовместимости его мировосприятия и армейского порядка. Куприн - профессиональный военный, в детские годы обучался в московском Втором кадетском корпусе, в семнадцать лет был зачислен в Александровское военное училище, после окончания которого в 1990 г. начал службу в 46-м Днепровском пехотном полку, дислоцированном в Подольской губернии, в чине подпоручика, затем поручика. Быт и нравы армии в прозе Куприна и Грина представляют собой художественное описание личного эмпирически приобретенного опыта.

Куприн изображает солдата как жертву армейской системы. В «Дознании» показан солдаттатарин Байгузин, из-за кражи пары голенищ и тридцати семи копеек наказанный стами ударами розог. Один из персонажей «Ночной смены» - жалкий, грязный солдат-татарин Камафутдинов, посмешище роты и раздражитель взводного, он не в силах произнести армейские термины вроде «малокалиберная», «скорострельная», «пехотная винтовка», «скользящий затвор». Сходный образ солдата- 
татарина, не приспособившегося к армейской жизни, есть и в «Поединке». Также в «Поединке» дана история рядового Хлебникова; он жалок, ему адресованы злые шутки, его избивает фельдфебель. Не дается солдатская наука рядовому Меркулову из «Ночной смены», за что он терпит оскорбления, рукоприкладство фельдфебеля. По сути, солдаты в прозе Куприна-жертвы этического нигилизма воинского начальства, чья поведенческая практика выходит за рамки нормы, но является регулятором межличностных отношений.

В «Ночной смене», например, в сказках старого солдата Замошникова, или в трио солдат, согласно поющих грустную деревенскую песню, или в поэтичных мотивах сна дневального Меркулова развернута тема талантливой, умной натуры солдата. Но в армейской прозе Куприна описано, как из человека выдавливается его индивидуальность, как в сознании рядового разрастается конфликт между двумя состояниями - отношением к себе как к личности и «деперсонализацией» [8, с. 69], при которой ломается самовосприятие, отчуждается «я», вместо него внутренний мир наполняется пустотой и ощущением себя стандартным элементом массы.

В произведениях Куприна психологическая задавленность солдата передана через поведенческие и портретные характеристики. Например, «Этот защитник отечества был худ и мал, точно двенадцатилетний мальчик. Его детское лицо, коричневое, скуластое и совсем безволосое, смешно и жалко выглядывало из непомерно широкой серой шинели с рукавами по колени, в которой Байгузин болтался, как горошина в стручке. Глаз его не было видно, потому что он их все время держал опущенными» $[10$, с. 150]. В сильную семантическую позицию Куприн ставит лексемы «жалко», «опущенными»; несовместимость естества человека и размера шинели подчеркивает его чужеродность, неуместность в устоявшемся армейском режиме. В эпизоде экзекуции Куприн опять приводит портретные характеристики, подчеркивающие незащищенность солдата: «Тело у него было черное и до странности худое», «в голосе его отозвалось страдание истязуемого молодого тела» [10, с. 156, 157]. Страдание Хлебникова передано через концентрацию психофизических деталей: «Хлебников поглядел на него растерянным, диким взором, но тотчас отвернулся. Губы его чмокнули, медленно раскрылись, и из них вырвалось короткое, бессмысленное хрипение $<\ldots>$ Солдат, точно складной манекен, как-то нелепо-легко и послушно упал на мокрую траву, рядом с подпоручиком. <..> Хлебников молчал, сидя в неловкой позе с неестественно выпрямленными ногами. <...> Опять послышался подпоручику короткий хриплый звук» [11, с. 169].

Ключевая повествовательная эмоция в описании жизни рядового - жалость, которую проявляет молодой офицер: Козловский в «Дознании», Ромашов в «Поединке». Оба героя - протогонисты и резонеры Куприна, в прошлом офицера. В его произведениях о солдатчине есть «освободительный дух» [13, с. 465], их гуманистический смысл выражен, например, во внутреннем монологе Ромашова: «серые Хлебниковы с их однообразно-покорными и обессмысленными лицами - на самом деле живые люди, а не механические величины, называемые ротой, батальоном, полком...» [11, с. 172].

В противоположность изображенным Куприным низшим воинским чинам, для Козловского и Ромашова регулятором отношений является совесть. Такого героя-двойника нет в рассказах Гринасолдата. В армейской прозе Куприна раскрывается глубина внутреннего мира офицера, он оттеняет психическое состояние солдата. Как отмечает А. Варламов, в отличие от изображения солдатчины Грином, в прозе Куприна дано «богатство человеческих натур» [2, с. 31], контрастирующих с армейской казенщиной.

В проблематике военных произведений Куприна и Грина есть существенное различие, которое мы соотносим с политическим выбором Грина: во время пребывания в армии он приобщился к эсеровскому движению. В герое Грина индивидуальность проявляется сильнее деперсонализации, его солдат - человек противодействия. В автобиографическом очерке «Тюремная старина» (1933) он признался, что его «служба прошла под знаком беспрерывного и неистового бунта против насилия» [5, с. 636]. В рассказе «История одного убийства» описано возмездие солдата-крестьянина Банникова, совершенное над ефрейтором Цаплей. В отстаивании прав солдата Грин шел за Куприным, который «один из первых заговорил о бесправном положении русского солдата, жестоко истязуемого за самую ничтожную провинность» [9, с. 9]. Описание Куприным участи солдата созвучно рассказу Л. Толстого «После бала» (изд. 1911). Разрешения конфликта между рядовым и старшим по званию через сопротивление злу силою, проявление воли со стороны рядового нет ни в рассказе Толстого, ни в произведениях Куприна. Куприн воспринимал армейскую службу как бремя, которое он не принимал нравственно, но которое надо перетерпеть [3, с. 68]. 
В произведениях Грина и Куприна решается вопрос о сложившемся в социуме уничижительном отношении к бесправному, о природной потребности мелкого чина доминировать над солдатом, о проявлении жажды власти, о психологических пределах терпения. По словам Грина, «мелкое солдатское начальство: ефрейтор, унтер-офицер, фельдфебель, - подгоняемые сверху, окончательно осточертели и походя срывали злобу на более робких и забитых» [4, с. 61$]$.

Ефрейтор Цапля в «Истории одного убийства» - человек вульгарный. Скука армейского существования побуждает его к куражу, жертвой которого должен стать солдат Банников. Скука, по мысли Л. Свендсена, - «не только внутреннее состояние, но также свойство окружающего мира» [15, с. 20]. Но Грин не интерпретирует ее как некое экзистенциальное начало, философскую проблему, «сложный и неоднозначно трактуемый феномен» [14, с. 5]; он понимает ее как проблему неразвитой нравственно личности, отсутствия культуры, он не соотносит ее с меланхолией, традиционно «связанной с мудростью, чувственностью и красотой» $[15$, с. 26]. В описании примитивности Цапли Грин ввел в текст ряды прямых авторских характеристик. Цапля считает, что имеет право жестоко обращаться с рядовым. Для него выходом из состояния скуки становится умножение коварства: он планирует украсть затвор у стоявшего на посту Банникова. Однако Грин выстраивает сюжет на противопоставлении намерения и результата: Банников приставляет штык к затылку Цапли, инцидент заканчивается гибелью ефрейтора.

Солдат Банников показан «грамотным, добродушным крестьянином, застенчивым и мягким» [4, с. 354], он исполнителен, безропотно угождает начальству, понимает, что «покорность и угодливость - козыри в жизненной игре» [4, с.354]. Вместе с тем Грин отмечает границы его покорности.

Реакция Банникова на оскорбления выражена в следующих синтаксических конструкциях: «Чего же вы ругаетесь, господин отделенный? - Я же ведь ничего...» «За что вы меня ударили, отделенный? А? За что?..» «-За что? Я же ничего...» [4, с. 359-361]. Вопросам придан риторический смысл, они не содержат намерения узнать причину расправы, но передают несогласие с поступком ефрейтора. Тройной вопрос во второй цитате передает степень обиды. Повтор отрицания («ничего») свидетельствует о возрастающем внутреннем сопротивлении и воспринимается преамбулой к последующим событиям. В «Истории одного убийства» описаны и сам поступок, и изменения психологических состояний убийцы. Так, первый импульс мести выражен в «жаркой слабости», «мучительно сладкой дрожи» [4, с. 366], холодного ужаса во время удара штыком. Здесь побуждение к убийству сращивается со стрессом, в итоге сам акт мести выглядит подчиненным инстинкту. Последующее состояние персонажа передано через описание физических и психических реакций. Банников «сильнее нажал винтовку, удерживая бьющееся тело, потом с силой дернул вверх, отчего голова ефрейтора подскочила и стукнулась о землю равнодушным, тупым звуком» [4, с. 366]. Эмоциональная картина этого фрагмента противоположна приведенной выше; Банников действует спокойно, рационально. Грин выстраивает изображение состояния Банникова на принципе психологической бинарности. Например, герой чувствовал «странную пустоту в голове», в теле «тупую, пьяную легкость», но его руки были «холодные и дрожали» [4, с. 366-367]. Последняя характеристика минимизирует приведенные выше признаки психологического выгорания. Конечной эмоцией в лаконичном по объему, но насыщенном по сути описании психики Банникова Грин выбирает «тяжелую, смертельную тревогу» [4, с. 367], но и она неоднозначна: герой, лукавя, ссылается на оправдательный, с точки зрения устава, мотив убийства якобы незнакомца и свистком вызывает разводящего.

В рассказе «Слон и Моська» содержание сфокусировано на жалком положении солдата Мосея Щеглова. Как персонажи Куприна, он не способен к военной науке, из-за страха ему с трудом даются стрельбы, ему адресованы насмешки, ругательства, он получает удары от фельдфебеля.

Детализирован диссонанс между физическими, душевными свойствами Мосея-крестьянина и унизительным страхом Моськи-солдата перед начальством. Грин выявляет в человеке индивидуальность, то, что «выходит за рамки его профессии, социальной и сословной принадлежности» [7, с. 212]. В деревне, где герой был личностью, его не называли дураком и хамом, он проявлял храбрость в экстремальных обстоятельствах; в Моське-солдате сохранена поэтизация крестьянского мира. В армии им овладевает комплекс неудачи и уныния, новый ротный доводит его до оцепенения, его армейское существование сопровождают психологические травмы. Грин поднял проблему, осмысленную в современной психологии (Е.П. Ильин «Психология страха», 2017): в ряде эпизодов страх перед ротным показан как защитная биологическая реакция человека. С точки зрения 3. Фрейда («Торможение, симптом, страх», 1926), в страхе проявляется психологическая беспомощность. Но в рассказе Грина генезис страха заключается в правовой беспомощности. 
Согласно популярному в России У. Джеймсу («Психология», 1911), во-первых, страх - грубая форма эмоции, во-вторых, в человеке сильна самость, которая синонимична личности; Джеймс пишет о таком проявлении самости, как воля и выбор. На примере армейской жизни героя Грина показано спонтанное преобладание выбора и воли над боязнью и страхом. В финальном эпизоде рассказа индивидуальность солдата берет верх над стадным чувством, им управляет не инстинкт самосохранения, но инстинкт правды: он обезоруживает ротного, тем самым спасает жизнь другого солдата и обрекает себя на бессрочную каторгу. Вся проза Грина обращена к персоналистическим ценностям - к человеку, его активной воле, устремленности к гармонии с собой и свободе, что проявилось в бунте Моськи. Как пишет персоналист Н. Бердяев, «в бунтарстве есть страсть к свободе» [1, с. 359].

Тема личного выбора была развита уже в первом рассказе Грина «Заслуга рядового Пантелеева». Ефрейтора Гришина совесть побуждает к душевным мукам после карательных действий против крестьян. Через изображение рефлексии персонажа Грин решает проблему этической и нравственной дилеммы. Страх перед каторгой не позволяет Гришину ослушаться приказа стрелять в мужиков, но последующие за этим переживания пробуждают в нем самость. Проявление ложной самости, а по сути обезличенности, показано в образе Пантелеева, уже после массового расстрела по приказу пьяного офицера застрелившего случайного крестьянина. Произведенный вследствие этого в младшие унтер-офицеры Пантелеев исполнен гордости: он «слуга и защитник царя и отечества от врагов внешних и внутренних» [6, с. 436]. Для Гришина он - Ирод.

Итак, в сюжетах Куприна солдат - пассивный персонаж, в рассказах Грина он совершает волевой поступок. При этом судьба гриновских и купринских солдат драматична. Даже в сюжете о Пантелееве не поставлена точка, мы не знаем, чем закончится его история. При этом поступки персонажей выполняют «содержательную», «изобразительную», а также изъяснительную, «оценочную функцию» [12, c. 177].

\section{СПИСОК ИСТОЧНИКОВ И ЛИТЕРАТУРЫ}

1. Бердяев Н.А. Самопознание // Бердяев Н. Судьба России. Самопознание. Ростов н/Д: Феникс, 1997. С. 308-344.

2. Варламов А.Н. Александр Грин. М.: Молодая гвардия, 2008. 450 с.

3. Вержбицкий Н.К. Светлая душа // Жизнь Александра Грина, рассказанная им самим и его современниками / Сост. В. Ковского. М.: Изд-во Литературного ин-та им. А.М. Горького; Феодосия: Изд. дом «Коктебель», 2012. C. $230-256$.

4. Грин А.С. Собр. соч.: В 5 т. / Сост., вступ. ст. В. Ковского; примеч. А. Ревякиной. М.: Художественная литература, 1991. Т. $1.703 \mathrm{c}$.

5. Грин А.С. Собр. соч.: В 5 т. / Сост., вступ. ст. В. Ковского; примеч. А. Ревякиной. М.: Художественная литература, 1991. T. 3.734 c.

6. Грин А.С. Собр. соч.: В 6 т. / Сост., вступ. ст. В. Вихрова; общая ред., послесл. и подготовка текста Вл. Россельса. М.: Правда, 1965. Т. 1. 463 с.

7. Есин А.Б. Психологизм // Введение в литературоведение. Литературное произведение: основные понятия и термины: учеб. пособие / Л.В. Чернец, В.Е. Хализев, С.Н. Бройтман и др.; под ред. Л.В. Чернец. М.: Высшая школа; Академия, 1999. С. 211-223.

8. Королева Е.Г., Василенко О.И. Деперсонализация-дереализация в рамках невротического расстройства. Случай из практики // Журнал Гродненского государственного медицинского университета. 2011. №2. С. 69-70.

9. Кулешов Ф.И. Вступительная статья Александр Иванович Куприн// Куприн А. И. Собр. соч.: В 9 т. / Сост., вступ. ст. Ф.И. Кулешова; примеч. И.А. Питляр. М.: Художественная литература, 1970. Т. 1. С. 5-38.

10. Куприн А.И. Собр. соч.: В 9 т. / Сост., вступ. ст. Ф. И. Кулешова; примеч. И.А. Питляр. М.: Художественная литература, 1970. Т. $1.511 \mathrm{c}$

11. Куприн А.И. Собр. соч.: В 9 т. / Сост., вступ. ст. Ф. И. Кулешова; примеч. И.А. Питляр. М.: Художественная литература, 1970. Т. 4. 486 с.

12. Мартьянова С.А. Поведение персонажа // Введение в литературоведение. Литературное произведение: основные понятия и термины: Учеб. пособие / Л.В. Чернец, В.Е. Хализев, С. . Бройтман и др.; под ред. Л.В. Чернец. М.: Высш. шк.; Академия, 1999. С. 175-187.

13. Питляр И.А. Примечания // Куприн А.И. Собр. соч.: В 9 т. М.: Художественная литература, 1970. Т. 1. C. 479-509.

14. Посохова С.Т., Рохова Е.В. Скука как особое психическое состояние человека // Вестник Санкт-Петербургского университета. 2009. Сер. 12. Вып. 2. Ч. 1. С. 5-12.

15. Свендсен Л. Философия скуки / Пер. с норв. К. Мурадян. М.: Прогресс-Традиция, 2003. 256 с. 
Чжан Жуй, аспирант кафедры истории новейшей русской литературы и современного литературного процесса Московский государственный университет им. М. В. Ломоносова 119991, Россия, г. Москва, Ленинские горы, 1

E-mail: kristinaruirui@yandex.ru

\section{Zhang Rui ETHICAL AHD PSYCHOLOGICAL FACTOR IN ARMY PROSE BY A. KUPRIN AND A. GREEN}

DOI: $10.35634 / 2412-9534-2021-31-5-1099-1104$

The article concludes that Kuprin's prose has some influence on Green's work. The biographical basis of their army prose, the similarity of the authors' positions in describing the dramatic fate of a soldier and his psychological trauma, the suppression of his individuality by the army system, the conflict between self-awareness and depersonalization, the fear factor of a person who is naturally incapable of a military regime are pointed out. The following differences are noted: Kuprin reinforces the motive of pity for the humiliated soldier at the expense of the motive of sympathy for him by a young military officer - a protogonist and reasoner; in Green's stories, the characters don't have double identities; Green's social revolutionary views led to the appearance of a rebel soldier in his stories, but the soldier is a passive character in Kuprin's stories.

Keywords: A. Green, A. Kuprin, individuality, solder image, boredom, conscience, fear.

\section{REFERENCES}

1. Berdyaev N.A. Samopoznanie. [Self-knowledge]. // Berdyaev N. Sud'ba Rossii. Samopoznanie. [The fate of Russia. Self-knowledge]. Rostov n/D: Feniks, 1997. pp. 308-344. (In Russian)

2. Varlamov A.N. Aleksandr Grin. [Alexander Green]. M.: Molodaya gvardiya, 2008. 450 p. (In Russian)

3. Verzhbickij N.K. Svetlayadusha. [Light soul]. // Zhizn' Aleksandra Grina, rasskazannaya im samim i ego sovremennikami. [The life of Alexander Green, told by himself and his contemporaries]. / Sost. V. Kovskogo. M.: Izd-vo Literaturnogo in-ta im. A.M. Gor'kogo; Feodosiya: Izd. dom «Koktebel'», 2012. pp. 230-256. (In Russian)

4. Grin A.S. Sobr. soch. [Collected works]: V 5 t. / Sost., vstup. st. V. Kovskogo; primech. A. Revyakinoj. M.: Hudozhestvennaya literatura, 1991. T. 1. 703 p. (In Russian)

5. Grin A.S. Sobr. soch. [Collected works]: V 5 t. / Sost.,vstup. st. V. Kovskogo; primech. A. Revyakinoj. M.: Hudozhestvennayaliteratura, 1991. T. 3.734 p. (In Russian)

6. Grin A.S. Sobr. soch. [Collected works]: V 6 t. / Sost.,vstup. st. V. Vihrova; obshchaya red., poslesl. I podgotovka teksta Vl. Rossel'sa. M.: Pravda, 1965. T. 1. 463 p. (In Russian)

7. Esin A.B. Psihologizm. [Psychologism] // Vvedenie v literaturovedenie. Literaturnoe proizvedenie: osnovnye ponyatiya i terminy. [Introduction to Literary Studies. Literary work: basic concepts and terms].: Ucheb. posobie / L.V. Chernec, V.E. Halizev, S.N. Brojtmani dr.; pod red. L.V. Chernec. M.: Vysshayashkola; Akademiya, 1999. pp. 211-223. (In Russian)

8. Koroleva E.G., Vasilenko O.I. Depersonalizaciya-derealizaciya v ramkakh nevroticheskogo rasstrojstva. Sluchaj iz praktiki. [Depersonalization-derealization within the framework of a neurotic disorder. Case from practice] // Zhurnal Grodnenskogo gosudarstvennogo medicinskogo universiteta. 2011. № 2. pp. 69-70. (In Russian)

9. Kuleshov F.I. Vstupitel'naya stat'ya Aleksandr Ivanovich Kuprin. [Introductory article Alexander Ivanovich Kuprin] // Kuprin A.I. Sobr. Soch. [Collected works]: V 9 t. / Sost., vstup. st. F.I. Kuleshova; primech. I.A. Pitlyar. M.: Hudozhestvennaya literatura, 1970. T. 1.pp. 5-38. (In Russian)

10. Kuprin A.I. Sobr. soch. [Collected works]: V 9 t. / Sost., vstup. st. F.I. Kuleshova; primech. I.A. Pitlyar. M.: Hudozhestvennaya literatura, 1970. T. 1. 511 p. (In Russian)

11. Kuprin A.I. Sobr. soch. [Collected works]: V 9 t. / Sost., vstup. st. F.I. Kuleshova; primech. I.A. Pitlyar. M.: Hudozhestvennaya literatura, 1970. T. 4. 486 p. (In Russian)

12. Mart'yanova S.A. Povedenie personazha. [Character behavior]. // Vvedenie v literaturovedenie. Literaturnoe proizvedenie: osnovnye ponyatiya i terminy. [Introduction to Literary Studies. Literary work: basic concepts and terms]: Ucheb. posobie / L.V. Chernec, V. E. Khalizev, S.N. Brojtman i dr.; Pod red. L.V. Chernec. M.: Vyssh. shk.; Akademiya, 1999. pp. 175-187. (In Russian)

13. Pitlyar I.A. Primechaniya. [Notes]. // Kuprin A. I. Sobr. soch. [Collected works]. : V 9 t. M.: Hudozhestvennaya literatura, 1970. T. 1. pp. 479-509. (In Russian)

14. Posohova S.T., Rohova E.V. Skuka kak osoboe psihicheskoe sostoyanie cheloveka. [Boredom as a special mental state of a person]. // Vestnik Sankt-Peterburgskogo universiteta. 2009. Ser. 12. Vyp. 2. CH. 1. pp. 5-12. (In Russian) 
15. 3Svendsen L. Filosofiyaskuki. [The philosophy of boredom]. / Per. s norv. K. Muradyan. M.: Progress-Tradiciya, 2003. 256p. (In Russian)

Zhang Rui, postgraduate student at Department of History of Modern Russian Literature and Modern Literary Process

M.V. Lomonosov Moscow State University

Leninskie Gory, 1, Moscow, Russian, 119991

E-mail: kristinaruirui@yandex.ru 